East African Medical Journal Vol. 77 No. 1 January 2000

FORENSIC MEDICINE IN KENYA: A PERSONAL VIEW

A. O. K. Olumbe, MBChB, MMed., DMJ (Path), Dip. Forens. Med. (RCPA) Head Medico-Legal Department, Ministry of Health, P. O. Box 21953, Nairobi.

\title{
FORENSIC MEDICINE IN KENYA: A PERSONAL VIEW
}

\section{A. O. K. OLUMBE}

\section{HISTORICAL BACKGROUND}

Forensic medical services in Kenya are not modeled on the coronial or medical examiners systems of the English speaking regions of the world. The current structure straddles the Police, the Ministry of Health and the Local council in the cosmopolitan areas. The former colonialists established this structure and since then there have been no significant changes. Before 1963 (prior to independence), the system was managed by the governor and all the personnel, ranging from the police to the magistrates, were hand picked to solve a particular crisis of concern to those in power. After independence, the primary concern was to train locals to attain the professional qualifications to enable the proper operation of the system. The main concern in relation to health care was preventive medicine, leaving forensic interests lagging behind. The City Mortuary, built during the colonial days in Nairobi, handles the bulk of the forensic cases in the city as well as those from the countryside surrounding districts, which are of paramount interest to the public and the surrounding districts. It is managed and staffed by the local government whose primary concern is the storage of the bodies. The revenue collected from the City Mortuary is substantial but unfortunately none is used to improve the services and the facilities. It was built to cater for 145 bodies when the population of the city was less than one million people. Furthermore, the Ministry of Health who also pays their monthly wages provides the full-time doctors who carry out the autopsies. These doctors are at a disadvantage by the lack of administrative control, proper office space and large workload.

All forensic cases are reported to the police who collect the bodies and transfer them to the City Mortuary. If they are in the countryside, they are transported to the local hospital mortuaries. Magistrates appointed by the Chief Magistrates in each district carry out the duties of a coroner.

\section{PRESENT SYSTEM}

Death examined at the City Mortuary include sudden deaths (the commonest category), accidental and violent deaths, deaths under suspicious circumstances including medical misadventures, deaths found within or brought into the territory, deaths in official custody and deaths due to execution of an offender. These criteria are similar to those laid down by the colonialists and those in the Western countries. The Chief Magistrates have considerable discretion but are obliged to hold a public inquest following an execution of a person under death sentence, if a person dies suddenly and unexpectedly in official custody and when required to do so by the Attorney General. Inquests may be held with or without a jury. In most cases the magistrates are deprived of adequate information and thus the opportunity to draw important conclusions, for instance, in relation to industrial accidents which could be prevented. This means society misses out on the benefits of recommendations, which if implemented could avert major workplace accidents.

As an indication of the workload involved, when the author worked at the City Mortuary from September 1993 to December 1994, he was responsible for at least 2,800 natural deaths, 400 motor vehicle accidents and 275 homicides. This is in addition to cases handled by two other doctors in the same period and those deaths that have resulted in autopsies being waived. The waiver of autopsy procedure is peculiar in the sense that the decision is made by the mortuary superintendent, hand picked by the local council officials, who lacks the legal and medical knowledge to make such decisions. Immediately prior to the autopsy, the "pathologist" (general practitioner) interviews two relatives of the deceased and the investigating police officer who often appears disinterested. If, after conducting the interview, viewing the body and reviewing any available documentation, the pathologist is satisfied of both the cause of death and that death is due to natural causes, he or she completes the police form A2. This is used in all the cases. Hence there are no special forms for waiver of an autopsy. In some cases, the mortuary superintendent issues the death certificates without the knowledge of the pathologist who is then asked to fill the form A2 retrospectively, using the cause of death on the "death certificate". The classification of the deaths, issuing burial or cremation orders, controlling exhumations and giving permission for bodies to be shipped out of the country are all under the jurisdiction of the mortuary superintendent. As there are no laws permitting the removal of tissues and organs for transplantation in the country, this service is not available.

\section{FORENSIC PATHOLOGY}

Forensic pathology in Nairobi is a division of National Public Health Laboratory Services of the 
Ministry of Health of the Kenyan Government. Until recently, there have been only two full-time government employed doctors neither of who have forensic training to carry out the autopsies. They do not have any postgraduate qualifications but merely the basic degree of Bachelor of Medicine and Bachelor of Surgery. About two years ago, there was only one doctor who had the postgraduate Diploma of Medical Jurisprudence (DMJ) of the Societies of Apothecaries (UK). He has since retired leaving the forensic services in further disarray. The consultant pathologists who have membership of the Royal College of Pathologists (UK) are involved in the University of Nairobi and other private enterprises and only come onto the scene when they are hired as defense pathologists. There is no provision within the University of Nairobi postgraduate programme for training in forensic pathology.

The doctors who work at the City Mortuary are posted to the department by the Government regardless of whether they have indicated forensic pathology as their first choice of specialty. In fact, in most occasions, it is a disciplinary measure for those who have failed to honour their postings into the country's district hospitals. About twelve years ago, a training programme for pathology and microbiology was enacted. The first year of this three-year course is spent in all the disciplines of pathology (surgical pathology and immunology, haematology, microbiology and clinical chemistry) and the final two years involve the rotation in all those disciplines for six months. During their rotation in surgical pathology, the registrars only gain experience of hospital autopsies. This programme has a high drop-out and failure rate, especially during the first year, due to the difficulty of the course and the doctors who do finish the course, are assigned to the government hospitals without any prospects of the lucrative private practice.

The Government Forensic Pathologist handles all the forensic pathologist's workload in Nairobi, including all criminal or suspicious cases, with the back up of the Government Forensic Laboratory which includes the Government Chemist who handle the toxicological cases. The latter is under the auspices of the Office of the President. Tight secrecy of this office as an issue deprives the pathologist of the toxicological results he expects to summarise immediately after conducting the post mortem before concluding the autopsy. Country cases other than homicides are handled by the "pathologists" (general practitioners) at the government hospitals who do not have any prior training in forensic medicine or pathology. Most cases are deaths, which occur after hospital admission but fall into reportable category and are not suspicious. However most doctors shy away from this work and those who are allocated these duties are regarded as undisciplined doctors "lacking" in clinical skills.

\section{FURTHER COMMENTS}

The main problem is that there is no specifically appointed coroner to investigate deaths and there is heavy reliance by the judicial system on the police to conduct the death investigations. Dishonesty among the police officers and inadequate pre-colonial investigation by them has culminated in magistrates not having complete control of the investigations. There are also long delays before investigations are complete and the heavy police workload naturally means little priority is given to criminal or suspicious deaths. Though these cases represent the minority of those reported, police may well not have the time, staff or resources to fully investigate natural or accidental deaths. Also, no set procedures have been established for the investigation of most of the reported deaths. If an investigation is inadequate, then it is difficult for meaningful recommendations to be made at an inquest that may ensue.

Kenya would seem to be a good candidate for the medical examiner type system found in the USA and Canada or the coronial system of the UK and Australia. The medical examiner system has trained death investigators as an integral part of its departments together with full forensic service facilities. The medical examiners have complete control over the investigations, including the holding of an inquest and making of recommendations where relevant. This type of system would alleviate numerous problems of the Nairobi system of death investigation.

The current capacity of City Mortuary must be improved to meet the needs of Nairobi, which has a population of more than three million. An integrated management approach should involve the doctors in all cases that are admitted to the mortuary. An important step would be for all the staff at the City Mortuary to have one employer within the judicial system.

Pertaining to forensic pathology in Nairobi, a formal postgraduate training programme for those who have qualified in Master of Medicine in Pathology is required. This would enable doctors to become consultant forensic pathologist such as in Australia for instance where the requirements are Fellowship of the Royal College of Australasia (FRCPA) with a diploma in forensic pathology following a one year attachment to a forensic institute or FRCPA with slant towards forensic pathology. It would be appropriate for the postgraduate registrars in pathology in the current Masters of Medicine (Pathology) programme to be attached to the City Mortuary for a stint of at least three months during their rotation. Similarly, those who have attained the Masters in Medicine (Pathology) could be attached to the City Mortuary for at least six months before they get attachments abroad in forensic institute (followed by a Diploma in Forensic Pathology, 
the DMJ or the newly created Diploma of Forensic Medicine from the Royal College of Pathologists of Australasia). It should be emphasised that an apprenticeship in histopathology is definitely desirable in the improvement of the training program for a forensic pathologist.

Another problem is the lack of an academic forensic pathology department in the University of Nairobi. This situation is not unusual in this region of the world and there are similarities even in developed countries where academic forensic pathology has been on the decline for some years. Indeed, several universities have lost their departments. The creation of such a department in the University of Nairobi would greatly strengthen the discipline for those who provide an important independent avenue of second opinion in difficult and controversial cases. University and Government departments working in cooperation would greatly improve standards.
For a developing country like Kenya, the primary aim of the Government is preventive medicine. Forensic services are therefore usually put last on the agenda until there is a crisis involving a case with political connotations. The working arena for a few handicapped doctors who have the onus of carrying out the autopsies in a hostile environment is complex since it involves interference in decisions and frustration of human rights. Developed countries must do more than work as "watch dogs" in protecting the doctors working in such situations. They should assist by providing proper facilities for forensic work and opportunities for training personnel.

\section{ACKNOWLEDGEMENTS}

To Professor Stephen Cordner and the late Emeritus Professor Edmondo Guli of Victorian Institute of Forensic Medicine, Melbourne for reading the manuscript.

\section{ANNOUNCEMENT}

\section{KENYA OBSTETRICAL AND GYNAECOLOGICAL SOCIETY}

\section{announces}

THE 25TH ANNUAL SCIENTIFIC CONFERENCE

Venue: Whitesands Hotel, Mombasa

Date: 23rd - 25th February, 2000

Theme: HIV/AIDS, Sexual and Reproductive Health in the twenty first century

Call for papers

Abstracts to be submitted by 15 th December, 1999

For further information contact

Secretariat

Kenya Obstetrical and Gynaecological Society

P.O. Box 19459

Nairobi, Kenya 